\title{
A METHOD TO PREDICT CHANGE PROPAGATION WITHIN BUILDING INFORMATION MODEL
}

\author{
Lama Adel SAOUD ${ }^{\mathrm{a}}$, Jamal OMRAN ${ }^{\mathrm{a}}$, Bassam HASSAN ${ }^{\mathrm{a}}$, Tatjana VILUTIENE ${ }^{\mathrm{b}}$, \\ Arvydas KIAULAKIS ${ }^{\mathrm{b}}$ \\ ${ }^{a}$ Engineering and Construction Management Department, Faculty of Civil Engineering, \\ Tishreen University, Lattakia, Syria \\ ${ }^{b}$ Department of Construction Technology and Management, Faculty of Civil Engineering, \\ Vilnius Gediminas Technical University, Sauletekio al. 11, LT-10223 Vilnius, Lithuania
}

Received 03 Feb 2017; accepted 19 Apr 2017

\begin{abstract}
This study examines problem of the management of design changes caused by the complexity of the design process and the lack of knowledge of all aspects of the design dependencies. This paper addresses the subject of design changes management in the context of a multidisciplinary collaborative environment of Building Information Modelling (BIM). Due to evolving role of BIM in designing of building projects and the increasing complexity of the design process a need to develop change management based on BIM methodology aroused. The application of BIM to construction projects has the potential to enhance the quality of information provided for making critical design decisions. Trusted change propagation is the key for successful change management. Paper describes developed method to predict the propagation of change through the building information model and provides the concept of visual technology to help designers to predict the change in the construction industry. The developed method includes the use of parameter-based Design Structure Matrix (DSM) as a tool for predicting change propagation. The novelty of research is the proposed integration of DSM with BIM to support the visual representation of predicting change within BIM. Case study demonstrates the possibilities of method in BIM environment.
\end{abstract}

Keywords: design change management, predicting change, change propagation, visualizing change propagation, Building Information Modelling (BIM), Design Structure Matrix (DSM).

\section{Introduction}

Change orders in construction industry are inevitable as it is hardly probable to deliver a project without any changes during both the design and implementation phases and this is reflected in the performance of the project in terms of cost, time and quality. Change is a complementary part of building design as the design process is repetitive in its nature and includes the investigation of many alternative solutions and impacts. An integrated or whole building design process involves analysis of the energy-related impacts and interactions of all building components, including the building location, structures, envelope, heating, HVAC, DHW, lighting, controls, and equipment and as well the impact of occupancy characteristics (Martinaitis et al. 2015). In spite of this, the cooperation of architects, engineers and constructors is very important during preparation of building design project and during the implementation phase. Unfortunately, due to the large number of participants the construction industry is characterized as a conservative and these results in fragmented decision-making process, innovation avoidance and missed opportunities (Motuzienè et al. 2016).
Studies have demonstrated that managing information flow is one of the critical aspects that affect the efficiency of the construction project, and even of the whole building lifecycle (Dave et al. 2016). Study of Derakhshanalavijeh and Teixeira (2017) revealed that improper planning and frequent design changes are among other main causes of cost overrun in construction industry. For that reason, efficient management of design changes is very necessary for the successful delivery of construction projects.

Building Information Modelling (BIM) is a novel technology in building design, based on parametric modelling, and a concept that intends to solve many problems related to design changes and data transfer to construction stage. During the construction phase, BIM engineers and managers, typically from the general contractor, execute BIM-related work but rarely share updated change information about as-built BIM models with other project and BIM engineers. Tracking and managing change information for as-built models effectively can improve BIM process management in construction, thereby eliminating

Corresponding author: Tatjana Vilutienè

E-mail: tatjana.vilutiene@vgtu.lt 
mistakes (Lin et al. 2016). BIM supports an increase in concurrency and the possibility for faster design iterations by increasing the ease of accessing, modifying and sharing design data. Otherwise, this has potential to create more engineering change and its propagation because of increased dynamic complexity in the overall design process; therefore, there will be a greater need to manage change effectively.

In complex systems where all parts are closely linked, changes to one part of a system are highly likely to result in a change to another part, which in turn can propagate further (Eckert et al. 2004). The greater the connectivity between systems, the greater is the chance that a change to one system leads to changes in other systems. Multiple changes can have interacting effects on other systems. This makes managing change processes a challenging problem. A denser network of dependencies between disciplines mainly causes the complexity of the design process. Therefore, the changes to one component can propagate through this network in several ways and affect components that are not directly linked to the initiating component. Understanding these direct and indirect links is essential for exact change risk assessment and successful change management. Only when the impact of a change has been predicted, the time, cost, and resources can be allocated.

Despite the great advantages of BIM in the detection of conflict, alerts and propagating changes in the model, editing objects and reloading updated links, the BIM tools support the management of change after it has been initiated. These tools do not foresee the spread of change and its impact, but they are merely tools to support the management of its execution.

This study examines problem of the management of design changes caused by the complexity of the design process and the lack of knowledge of all aspects of the design dependencies. Authors propose a method for predicting the effects of change in BIM environment. This method is based on modelling the change within the BIM, by using parameter-based design structure matrix as tool to represent relations of the dependencies between the design parameters in a way that will support a series of changes within the collaborative BIM environment. Study also provides the approach for visual representation of effects and propagation of change within BIM environment.

Proposed method will allow predicting the spread of change within the BIM environment in order to mitigate risks related to non-accurate assessment of the impact of design changes through correct modelling for the project and tools to represent dependencies, which can be integrated with BIM to support the visual representation of the predicted change in the construction industry.

\section{Literature review}

The application of BIM to construction projects has the potential to enhance the quality of information provided for making critical design decisions (Dowsett, Harty
2013). However, the highly fragmented design and construction process when differentiated stakeholders with disparate approaches participate make interdisciplinary work difficult at early stages of design.

A number of empirical studies to ascertain the importance of change in the design and development process presented recently. The results of many BIM application cases revealed clear improvement in engineering design quality, in terms of error-free drawings, and steadily increasing improvement in labour productivity (Sacks et al. 2010; Poirier et al. 2015); improved quality of work (Davies, Harty 2013); reduction of whole optimization process time (Asl et al. 2015); reduced energy consumption (Azhar et al. 2011); improved error prediction (Wang et al. 2016) and identification (Lee et al. 2012). Suermann and Issa (2009) assessed perceptions about the impact of the implementation of BIM on construction projects. Study revealed that more than $50 \%$ respondents pointed out that BIM applications in construction projects improves quality $(87.7 \%)$, cost $(83.7 \%)$, schedule $(82.8 \%)$, productivity $(74.9 \%)$, and safety $(53.7 \%)$ issues in comparison with non-BIM projects. The McGraw Hill (2009) basing on an internet survey of 2,228 responses of architects, engineers, contractors and owners reported that $77 \%$ of users perceived a positive ROI on their investment, $87 \%$ were experiencing a positive ROI and $93 \%$ believed there is more value to be realized in the future.

However, a few research efforts have made to understand the change management systems in the context of a BIM information model. Study by Lee et al. (2012) revealed that missing items were very likely to be identified without using BIM, whereas illogical design and discrepancies between drawings were relatively difficult to detect without using BIM. In the case of illogical design, almost $30 \%$ of errors were categorized as errors that had less than $25 \%$ likelihood of being identified without using BIM.

Although the potential benefits of BIM are clear, its integration in design and construction processes requires tenacity as well as careful planning and control. A variety of problems has occurred in many cases, including loss of data, difficulty in communication, and poor work efficiency (Oh et al. 2015). The difficulties experienced in exchanging information between architectural and precast engineering modelling systems (Sacks et al. 2010). The lack of effective design collaboration between the construction site and the off-site design office often leads to information delays in the design and construction processes, as well as confusion among different parties involved in these processes (Lin et al. 2016).

The advanced role for BIM in the construction industry made a need to understand better the requirements of change management in the BIM environment. A number of studies worked to address this need through evaluation of the effectiveness of the BIM-based system and its tools in design changes by indicators (Giel, Issa 2013), or by using questionnaires (Shourangiz et al. 2011). In addition, some researchers have treated change management 
issues by $4 \mathrm{D}$ or $5 \mathrm{D}$ models, which integrates time and cost in addition to 3D geometry, e.g. Jongeling and Olofsson (2007) suggested location-based scheduling though planning of workflow and integration with 4D CAD design models.

Apart from the BIM, one method to assist engineering change management is prediction of its impact. The problem of design change propagation prediction is more often arise in industry were changes in the complex product design can generate significant impacts on the product development cycle. The problem of prediction of change propagation was analysed in various industry design cases. Researchers suggested a number of prediction tools based on the concept that change propagates between elements through the linkages between them. Sun et al. (2006) suggested tools to predict change events within the organizational approach based on the dependency relationships between these main elements: 1) project characteristics that lead to the change; 2) causes of the change; 3) the likelihood of change occurrence; and 4) the change consequences. Based on a detailed case study, Eckert et al. (2004) presented a comprehensive analysis of the problems and processes associated with product change in the aerospace industry. Li et al. (2012) developed the process model and simulation algorithms for change propagations in the motor cycle engine design process. Ma et al. (2016) proposed design change analysis model (DCAM) that enables quantifying the change propagation impact and applied it for mechanical product development. Shankar et al. (2012) analysed change records of original equipment manufacturers and concluded that $32.4 \%$ of the total changes were due to propagated changes. They found that $77.0 \%$ of changes were due to internal reasons, while the remaining $23.0 \%$ were external. The majority of reasons for these propagated changes include document error rectification such as drawing errors, incorrect introduction date, and design error rectification such as design limitations. The findings indicated nearly one-third of time spent by the engineers can be reduced by developing appropriate controls during the change release process.

Since change propagation causes uncertainty in design time, cost, and quality, thus needs to be predicted and controlled. Therefore, it is necessary to find the most optimal path for design changes to propagate along in order to reduce their impacts on the design process as much as possible. Different methods and tools trying to model change propagation and support change prediction and analysis have been developed during the last decade. Some tools use the network of elements (i.e. systems, components, or attributes) linked by dependences (i.e. structural, behavioural, and functional parameters) to support causal change propagation analysis and decision making (Hamraz et al. 2013). Others apply change propagation algorithms to support change prediction and based on numerical algorithms, which use quantified direct linkages between the elements to calculate the spread of changes across the network.
To forecast indirect change propagation the Change Prediction Method (CPM) has been developed by Clarkson et al. (2004). CPM computes the risk of change propagation between components within Design Structure Matrices (DSMs). In the first stage of this approach, two numerical DSMs capturing the likelihood and impact of change propagation between directly connected components are elicited through experience-based estimations from domain experts. The direct risk of change propagation is defined as the product of direct likelihood and direct impact. In the second stage, the combined risk of change propagation is calculated using a numerical search-based algorithm. The combined risk is the sum of the direct risk and indirect risk, which considers change spreading via intermediate parts. In the third stage, different stakeholders, e.g., the management, product design and development, sales and marketing, quality control, assembly, mechanical engineering, and manufacturing, to support decisions, can use the combined risk matrix.

DSMs have been used as the basis for modelling change propagation in complex design systems, by supplying the basic matrices with the likelihood of a change propagating and with the impact on the element. Zhao et al. (2008) used an activity-based DSM to model the information flows in a construction project and applied a Monte Carlo simulation algorithm to explore the probable rework of activities.

Current engineering change propagation models map the product connectivity into a single-domain network and model change propagation as spread within this network. Those models miss out most dependencies from other domains and suffer from "hidden dependencies". Hamraz et al. (2012) proposed the function-behaviourstructure (FBS) linkage model, which combines concepts of both the function-behaviour-structure model with the CPM.

Visualization methods were also used to represent the effects and propagation of change, where the effects can be visualized through networks or propagation trees (Keller et al. 2005). These networks represent the dependencies between the elements. The elements can form nodes in different domains, edges represent dependencies (inter or intra domain). The length of the edges can characterize different information, such as the combined risk or the shortest path.

In order to avoid changes to expensive subsystems change prediction can be used to support preventive decision-making and in planning project activities (Hamraz et al. 2012). Furthermore, change prediction can help at the tendering stage to estimate the cost of customization or modification of products. Whilst a number of approaches exist, which are able to predict change, there is still need for developments able to support the change management within BIM environment and enable visual representation of predictions. 


\section{Research methodology}

The specific methodology of this study is based on a literature review, a case study and face-to-face interviews (Table 1). Literature review was made having the aim to identify the change management methods that can integrate with the BIM tools. Selected change management methods described in Sections 2.1 and 2.2 applied in case study to illustrate change propagation in the context of BIM information model. Case study presented in Section 3 examines change management in the context of a multi-disciplinary collaborative BIM environment during the design stage. Additionally, to collect the data that is related to dependencies of design components and to determine the probability of change, the face-to-face interviews were conducted. As a result, a change model based on BIM was developed.

Table 1. Research framework of this study

\begin{tabular}{l|l|l}
\hline $\begin{array}{l}\text { Metho- } \\
\text { dology }\end{array}$ & \multicolumn{1}{|c}{ Purpose } & \multicolumn{1}{c}{ Outcomes } \\
\hline $\begin{array}{l}\text { Literature } \\
\text { review }\end{array}$ & $\begin{array}{l}\text { Identify change } \\
\text { management methods } \\
\text { that can integrate with } \\
\text { the BIM tools. }\end{array}$ & $\begin{array}{l}\text { Using parameter-based } \\
\text { DSM to represent } \\
\text { the dependencies and } \\
\text { CPM algorithm to } \\
\text { calculate the likelihood } \\
\text { of change. }\end{array}$ \\
$\begin{array}{l}\text { Case } \\
\text { study }\end{array}$ & $\begin{array}{l}\text { Understand the change } \\
\text { management systems } \\
\text { in the context of BIM } \\
\text { information model. }\end{array}$ & $\begin{array}{l}\text { Modelling of change } \\
\text { based on change } \\
\text { management systems } \\
\text { within the BIM. }\end{array}$ \\
$\begin{array}{l}\text { Face- } \\
\text { to-face } \\
\text { interviews } \\
\text { Collect data that is } \\
\text { related to dependencies } \\
\text { of design components } \\
\text { and probability of } \\
\text { change. }\end{array}$ & $\begin{array}{l}\text { Developing an } \\
\text { information model for } \\
\text { management of design } \\
\text { changes. }\end{array}$ \\
\hline
\end{tabular}

\subsection{Parameter-based DSM}

In 1981, DSM was introduced as a management tool by Steward (1981). It represents a system or a project and it allows the representation of the repetitive task dependencies in it, also DSM is a platform to analyse change propagation data, based on combined component links (Keller et al. 2005). DSM can represent dependencies at different design levels such as component, team, activity, parameter, etc. (Browning 2001).

Currently, BIM has strongly changed design and documentation methodologies. So, it has become necessary to identify new levels appropriate for representing information for DSM. Parameter-based DSM analyses design process at the level of design parameter relationships. Its applications include low-level activity sequencing and process construction, and sequencing of the design decisions.

The design of buildings is described as repetitive operations, and design changes, which are actually achieved at the lower levels (parameter level), as well as parametric BIM let to use parameter-based DSM in modelling the process of change and employing it as a platform to analyse change propagation data.

\subsection{Prediction of engineering change propagation}

Several algorithms to expect indirect change propagation have been developed, such as the CPM (Clarkson et al. 2004). CPM is a technique for calculating the combined risk, and uses a product of probability and impact of change, where DSM is provided with probable values of the occurrence and impact of the change. The likelihood of change is the average probability that a change in the design of one component will lead to a design change in another by propagation across the links between them. The impact is the average ratio of design work that will need to be redone if the change propagates. For example, a change in the design of beams may affect the redesign of $30 \%$ of the design of the columns.

A series of change propagation is generated by transmitting the influence of change from one component to another. The combined influence of change is defined as the sum of the direct and indirect effects. Figure 1 shows the difference between the two types of dependencies, and Figure 2 illustrates routes of propagation tree between sub-systems $a$ and $b$.

The original algorithms used in the CPM tool (Clarkson et al. 2004) calculated the combined likelihood through a method that tracked each possible route that could be followed from an initiating component to a specific affected component. The combined likelihood algorithm (see Fig. 3) built basing on propagation tree illustrated in Figure 2. In combined likelihood algorithm $l_{b a}$ denotes direct likelihood between $a$ and $b ; l_{b a(b d a)}$

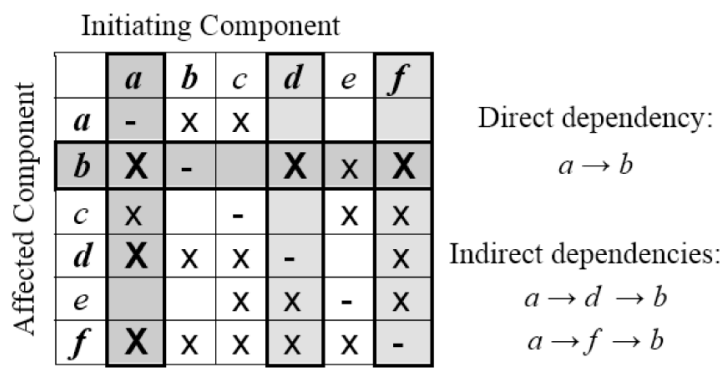

Fig. 1. Direct and indirect dependencies (adapted from Clarkson et al. 2004)

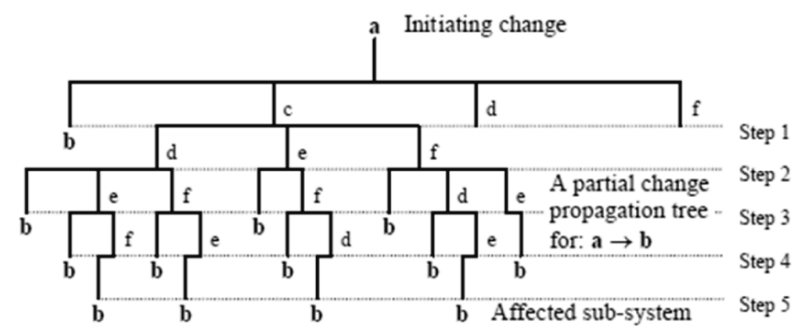

Fig. 2. A partial change propagation tree (adapted from Clarkson et al. 2004) 


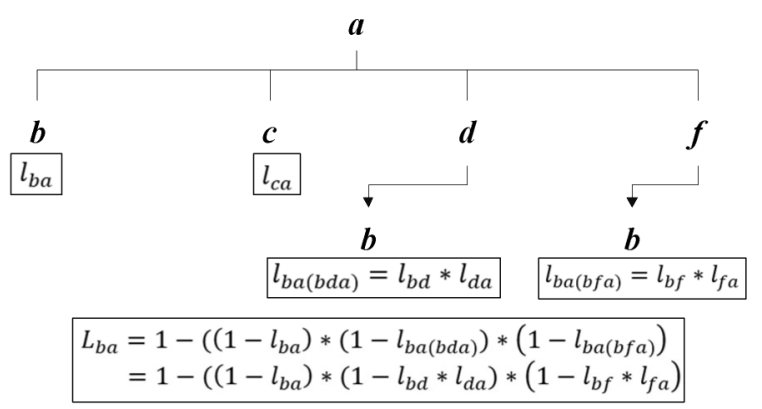

Fig. 3. Combined likelihood algorithm

denotes likelihood between $a$ and $b$ through track ( $b d a)$; $l_{b a(b f a)}$ denotes likelihood between $a$ and $b$ through track $(b f a)$, and combined likelihood between $a$ and $b$ marked as $L_{b a}$.

This research utilises presented algorithm to calculate the combined likelihood of change propagation from one component to another. Research deals with a realistic representation of the changed elements; the affected elements are the associated elements within the virtual BIM environment (i.e. there is possibility within BIM model to show, which columns will need to be redone if the change propagates). Proposed approach do not consider the probable values of the impact of the change, but consider the dependent relations between components within BIM, as well as the proportion of the likelihood of change.

\section{Case study}

Case study analyses the commercial building project, and examines change management in the context of a multidisciplinary collaborative BIM environment during the design stage.

This project was designed by using a Revit as one of the strongest design programs that rely on BIM. The project design team consists of architects, structural engineers and MEP (Mechanical, Electrical, and Plumbing) engineers. The coordination process of changes in information models was observed in design sessions. Numerous examples of changes encountered and BIM models
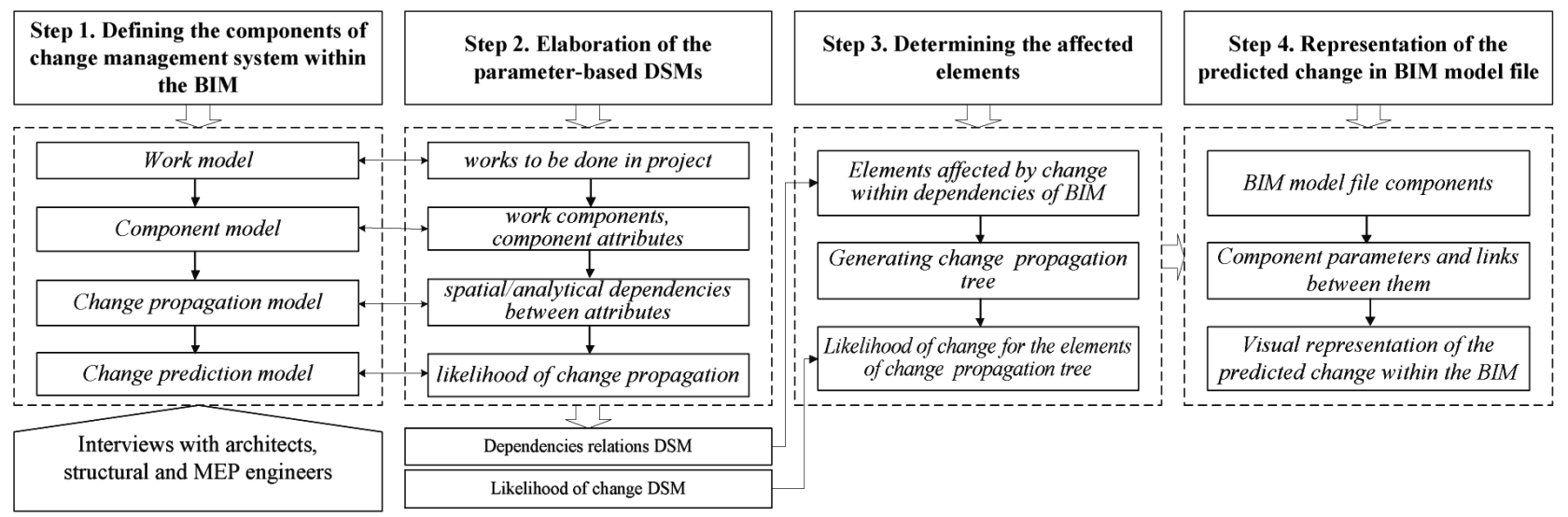

related to these changes were discussed and reviewed with the design engineers. This gave the opportunity to understand the change management systems in the context of BIM information model.

The basic reliance was made on detailed interviews with the professional designers in order to develop a change model based on BIM and to collect data related to dependencies of design components and probability of change. During the data collection process, it was observed that even professional designers had not enough knowledge about all aspects of the design. Collected data used to develop a model for management of design changes by using parameter-based design structure matrix.

The change prediction within BIM environment was done in following steps (see Fig. 4):

1. Modelling of change based on change management systems within the BIM. On this step, the components of change management systems within the BIM environment are defined.

2. Developing information model by using the parameter-based DSM to represent the relationships between design parameters in order to form the basis to analyse change propagation data.

3. Determining the elements affected by change within dependencies of BIM and calculating the likelihood of their change, using the CPM methodology.

4. Representing the change visually by integration of DSM with BIM programmatically.

\subsection{Modelling of change based on change management systems within the BIM}

During this step, the design references within BIM model and the design changes files were used. Based on observation of component parameters changes in the BIM model and with the assistance of design engineers in the company, component parameters have been grouped in groups called Changed Component Attributes, these attributes are component's geometry, position and specifications.

It was also noted that the changes in some of component attributes caused automatic changes in others by

Fig. 4. Steps of proposed methodology for change 
their relationships that are defined within the BIM information model. For example, the column is linked to the floor. Thus, if a change happens in a floor attribute (e.g. position), it will automatically update column attribute (e.g. geometry) which is connected with it because of a spatial relationship between them.

The changes between the components are caused by spatial or analytical dependencies, it must be noted here that the BIM information model is able to define a number of spatial dependencies between the components and a few analytical dependencies due to their complexity. During the interviews with engineers, they have confirmed that the probability of change in one component attribute due to change in another is small for some components attributes and large for others, this depends on the strength of interaction between them.

As the result of this study, the following models shown in Figures 5, 6, 7, and 8 were built. Unified Modelling Language (UML) is used to represent the diagrams. The Figure 5 shows the project works model, which consists of architecture, structure, and MEP works. The Figure 6 shows the work components model where each component has attributes specific to the geometry, position and specifications. The Figure 7 shows the change propagation model where the change propagates between the components attributes, which are linked with each other by spatial $(s)$ or analytical $(a)$ dependencies. The Figure 8 shows the change prediction model, where the change of an attribute expected due to change of other by potential value, which is called the likelihood of change propagation "l".

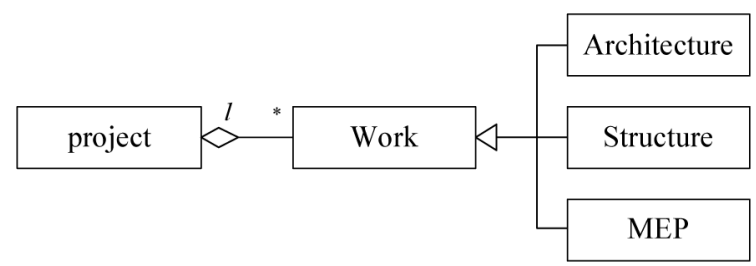

Fig. 5. Works' model

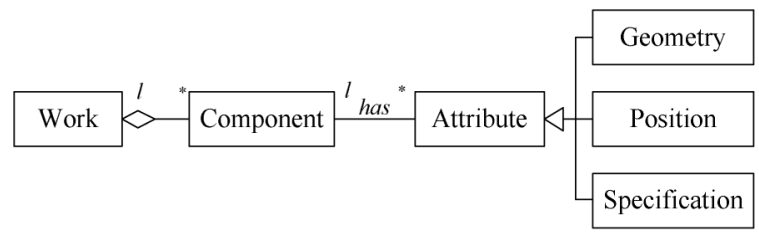

Fig. 6. Component model

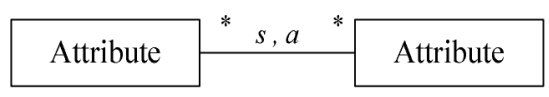

Fig. 7. Change propagation model

\begin{tabular}{|c|c|c|}
\hline & $\begin{array}{l}* \quad l \\
*\end{array}$ & Attrihute \\
\hline
\end{tabular}

Fig. 8. Change prediction model

\subsection{Development of an information model by using the parameter-based DSM}

\subsubsection{The system definition and scope}

The system studied in the case study is a commercial building system, that includes architectural, structural and MEP works. Each work consists of a set of components identified in collaboration with design engineers in the company.

Component attributes (geometry, position, specifications) have been identified at the level suitable for representation of information for DSM, to be able manage DSM and to reduce the complexity caused by the large volume of data in case of representation at the level of the parameter. Studied attributes are placed in the first row and the first column of the matrix (see Figs 9 and 10).

\subsubsection{Data collection}

Based on detailed interviews conducted in the company with multidisciplinary engineers, the data on the dependencies between the attributes was collected and the nature of these dependencies was discussed. The definition of dependencies was necessary for programming these relationships within the DSM in order to interact with Revit. In addition, the probabilities of change between the attributes were defined to form a matrix to predict the likelihood of change. In this context, likelihood is defined as the average probability that a change in the design of one component attribute will lead to a design change in another by propagation across their common interface.

\subsubsection{Production of the matrix}

After collecting data, a two-dimensional DSM was built to represent the structure of basic dependencies between the attributes of system components. Matrix cells were fed by the dependencies describing the type of relations between the attributes (Section 3.3.1 explains in detail these dependency relations) and the possibility of change based on the recorded data. Cell with value indicates the interaction between the attributes of different components.

The draft versions of the DSMs were shown to the participants and their comments were received. The models were finalized taking into account the feedbacks from the designers and engineers. A part of the resultant DSMs is shown in Figures 9 and 10. Figure 9 represents the dependency relations DSM, and Figure 10 represents the likelihood of change DSM.

Diagonal cells are inactive in usual DSM model, but the relationship with the component attribute itself is entered to adapt for working within the BIM environment. For example, changing the position of duct may change the position of other duct that is connected to (i.e. relation "join" in diagonal cell on intersection of $b$ row and $b$ column). 


\begin{tabular}{|c|c|c|c|c|c|c|c|c|c|c|c|c|c|c|c|c|c|c|c|c|c|c|}
\hline & & $a$ & b & c & d & e & $f$ & $\mathrm{~g}$ & h & i & $\mathrm{j}$ & $\mathrm{k}$ & 1 & $\mathbf{m}$ & $\mathrm{n}$ & o & $\mathrm{p}$ & $\mathbf{q}$ & $\mathbf{r}$ & $\mathbf{s}$ & $t$ & $\mathbf{u}$ \\
\hline beam $\mathbf{G}$ & a & & inter & & & inter & & & & & & & & & & & & & & & & inter \\
\hline duct $P$ & b & inter & join & & & & & join & & & & & & & & & & & & & & \\
\hline beam $\mathrm{S}$ & c & self & & & & & & & & & & & & & & & & & & & & \\
\hline column G & d & join & & & & & & & & & & & & & & & & & & & & \\
\hline ceiling $\mathbf{P}$ & e & & inter & & & & & & & & & & & & & & & & & & & inter \\
\hline space $\mathbf{G}$ & f & & & & & inter & & & & & & & & & & & & & & & & \\
\hline diffuser $P$ & g & & & & & host & & & s. host & & & & & & & & & & & & & \\
\hline $\begin{array}{l}\text { lighting } \\
\text { fixture } P\end{array}$ & h & & & & & host & & s.host & & & & & & & & & & & & & & \\
\hline column $S$ & $\mathbf{i}$ & & & & self & & & & & & & & & & & & & & & & & \\
\hline foundation $\mathrm{G}$ & $\mathbf{j}$ & & & & join & & & & & & & & & & & & & & & & & \\
\hline space SI & $\mathbf{k}$ & & & & & & self & & & & & & & & & & & & & & inter & \\
\hline space $S \mathrm{~m}$ & 1 & & & & & & self & & & & & & & & & & & & & & & \\
\hline foundation $S$ & $\mathbf{m}$ & & & & & & & & & & self & & & & & & & & & & & \\
\hline $\begin{array}{l}\text { lighting } \\
\text { fixture } S\end{array}$ & $\mathrm{n}$ & & & & & & & & & & & in & & & & & & & & & host & \\
\hline diffuser $\mathrm{S}$ & 0 & & & & & & & & & & & & in & & & & & & & & host & \\
\hline diffuser G & p & & & & & & & & & & & & in & & & s.sys & & & & & & \\
\hline $\begin{array}{c}\text { air handling } \\
\text { unit } S\end{array}$ & $q$ & & & & & & & & & & & & in & & & & & & & & & \\
\hline duct $S$ & $r$ & & & & & & & & & & & & & & & join & & join & & & & \\
\hline $\begin{array}{c}\text { lighting } \\
\text { fixture } G\end{array}$ & $\mathbf{s}$ & & & & & & & & & & & in & & & self & & & & & & & \\
\hline ceiling $S$ & $\mathbf{t}$ & & & & & & & & & & & & & & host & host & & & & & & \\
\hline duct $G$ & $\mathbf{u}$ & & & & & & & & & & & & & & & & join & & self & & & \\
\hline
\end{tabular}

Notations: G - geometry; P - position; S - specification; Sm - mechanical specification; S1 - lighting specification

Fig. 9. The dependency relations DSM

\begin{tabular}{|c|c|c|c|c|c|c|c|c|c|c|c|c|c|c|c|c|c|c|c|c|c|c|}
\hline & & a & b & $\mathbf{c}$ & d & e & $\mathrm{f}$ & g & $\mathrm{h}$ & i & $\mathrm{j}$ & k & 1 & $\mathrm{~m}$ & $\mathbf{n}$ & o & $\mathrm{p}$ & q & $r$ & $\mathbf{s}$ & $\mathbf{t}$ & $\mathbf{u}$ \\
\hline beam $\mathbf{G}$ & a & & 0.3 & & & 0.35 & & & & & & & & & & & & & & & & 0.75 \\
\hline duct $P$ & b & 0.8 & 1,0 & & & & & 0.95 & & & & & & & & & & & & & & \\
\hline beam $S$ & c & 0.95 & & & & & & & & & & & & & & & & & & & & \\
\hline column G & d & 0.6 & & & & & & & & & & & & & & & & & & & & \\
\hline ceiling $P$ & e & & 0.75 & & & & & & & & & & & & & & & & & & & 0.8 \\
\hline Space G & f & & & & & 1,0 & & & & & & & & & & & & & & & & \\
\hline diffuser $P$ & g & & & & & 1,0 & & & 0.5 & & & & & & & & & & & & & \\
\hline $\begin{array}{l}\text { lighting } \\
\text { fixture } P\end{array}$ & h & & & & & 1,0 & & 0.4 & & & & & & & & & & & & & & \\
\hline column $S$ & i & & & & 0.95 & & & & & & & & & & & & & & & & & \\
\hline foundation $\mathrm{G}$ & $\mathbf{j}$ & & & & 0.85 & & & & & & & & & & & & & & & & & \\
\hline space SI & $\mathbf{k}$ & & & & & & 0.5 & & & & & & & & & & & & & & 0.3 & \\
\hline space $\mathbf{S m}$ & 1 & & & & & & 0.7 & & & & & & & & & & & & & & & \\
\hline foundation $S$ & $\mathbf{m}$ & & & & & & & & & & 0.95 & & & & & & & & & & & \\
\hline $\begin{array}{l}\text { lighting } \\
\text { fixture } S\end{array}$ & n & & & & & & & & & & & 0.4 & & & & & & & & & 0.6 & \\
\hline diffuser $S$ & $\mathbf{0}$ & & & & & & & & & & & & 0.8 & & & & & & & & 0.7 & \\
\hline diffuser $G$ & $\mathrm{p}$ & & & & & & & & & & & & 0.5 & & & 0.6 & & & & & & \\
\hline $\begin{array}{c}\text { air handling } \\
\text { unit } S\end{array}$ & $q$ & & & & & & & & & & & & 0.3 & & & & & & & & & \\
\hline duct $S$ & $r$ & & & & & & & & & & & & & & & 1,0 & & 0.85 & & & & \\
\hline $\begin{array}{c}\text { lighting } \\
\text { fixture } G\end{array}$ & $\mathbf{s}$ & & & & & & & & & & & 0.7 & & & 0.9 & & & & & & & \\
\hline ceiling $\mathbf{S}$ & $t$ & & & & & & & & & & & & & & 0.4 & 0.3 & & & & & & \\
\hline duct $G$ & $\mathbf{u}$ & & & & & & & & & & & & & & & & 0.9 & & 0.85 & & & \\
\hline
\end{tabular}

Notations: $\mathrm{G}$ - geometry; $\mathrm{P}$ - position; $\mathrm{S}$ - specification; $\mathrm{Sm}$ - mechanical specification; $\mathrm{S}$ - lighting specification

Fig. 10. The likelihood of change DSM 


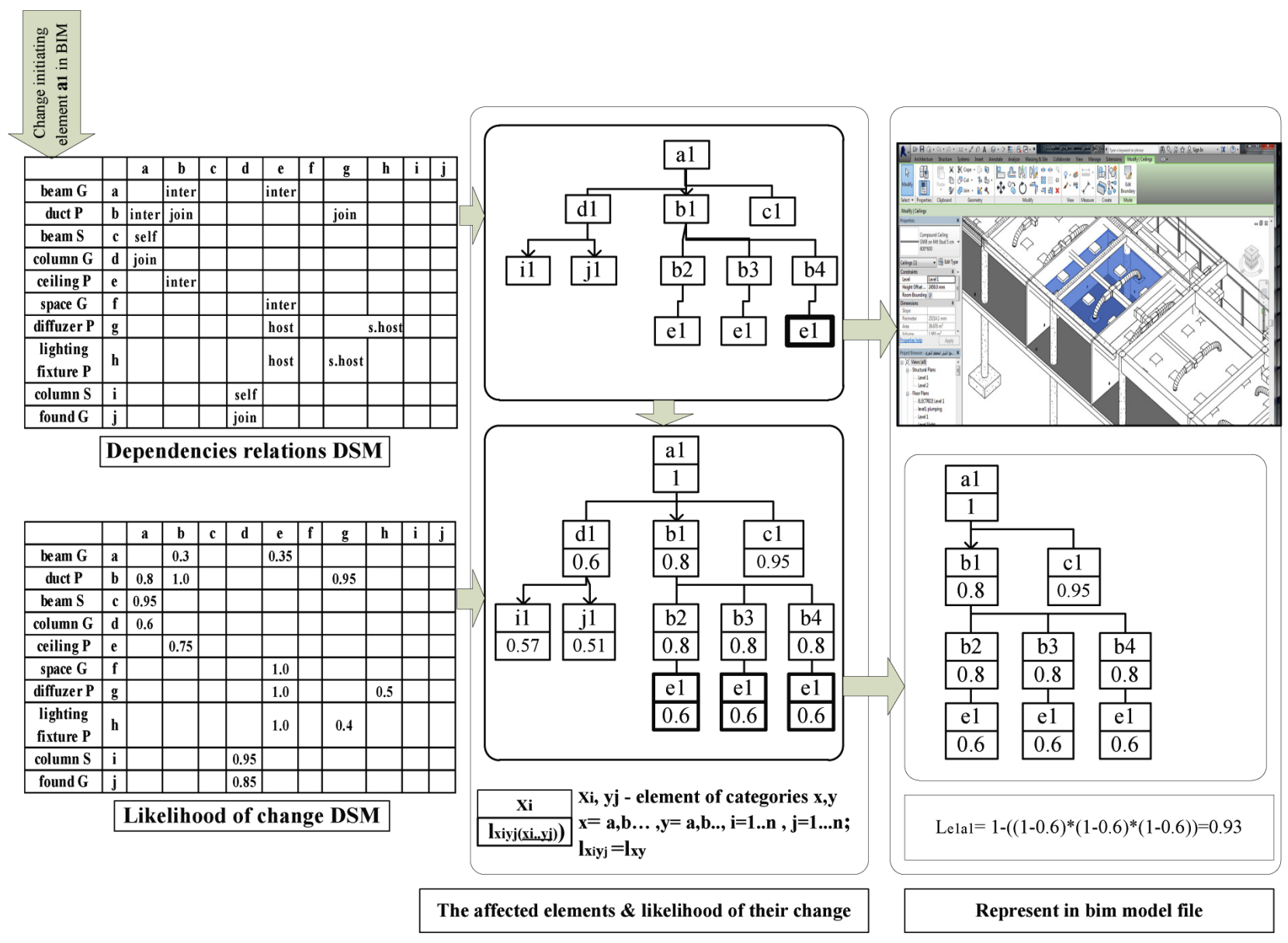

Fig. 11. Methodology applied for predicting change propagation

\subsection{Determination of elements affected by change and calculation of the likelihood of their change}

The following sections explain the methodology for determining the affected elements by change and calculating the probability of change based on the matrices of the resultant DSMs. Figure 11 shows methodology applied.

\subsubsection{Determination of the affected elements by change within dependencies of BIM and generating change prop- agation tree}

Track the spread of change within BIM requires that BIM define all the spatial and analytical dependencies between components. Previously mentioned that BIM information model has limited definition of spatial dependencies and lack of definition of the analytical dependencies.

Tracking the spatial dependencies is possible within Revit, they are either clearly defined within Revit as "host" relations or implicitly defined within the component parameters, so it will be searched as an " $i n$ " relation, for example, the lighting device has parameter that defines the room to which it belongs. There is also a group of non-defined relations within Revit, as an "inter" relations, for example, chiller element is not connected with the slab under it, although there is a face of chiller that is congruent to this slab. These relations are programmed by using properties such as adjacency and intersection between objects, where each component within Revit is represented by geometric shape, which has edges and faces, i.e. boundaries. These boundaries are completely defined by coordinates within the database.

The relation "self" that means relation within the same item was also defined. For example, change of the geometry of beam may change its specifications (e.g. reinforcing). Relation "join" denote that elements are connected to each other, such as columns and beams. Relation "s.host" denotes that the two elements have the same host element. Relation "s.sys" means that elements are defined in one system. All these relations are indicated within the matrix of dependencies (see Fig. 9).

The attributes linked by analytical relations are often linked by spatial relationship too. For example, according to the analytical relations, the changes in the specifications of the room space will change specifications of diffusers in this room (i.e. the attributes of diffusers, which are only associated with space of this room by spatial relationships, will change). So, the analytical relationships based on the spatial relationships between the elements were defined. Identifying the elements, which attributes affected by change, requires knowledge of how elements connect spatially, and these relations were defined within the Revit environment by above-mentioned ways. 


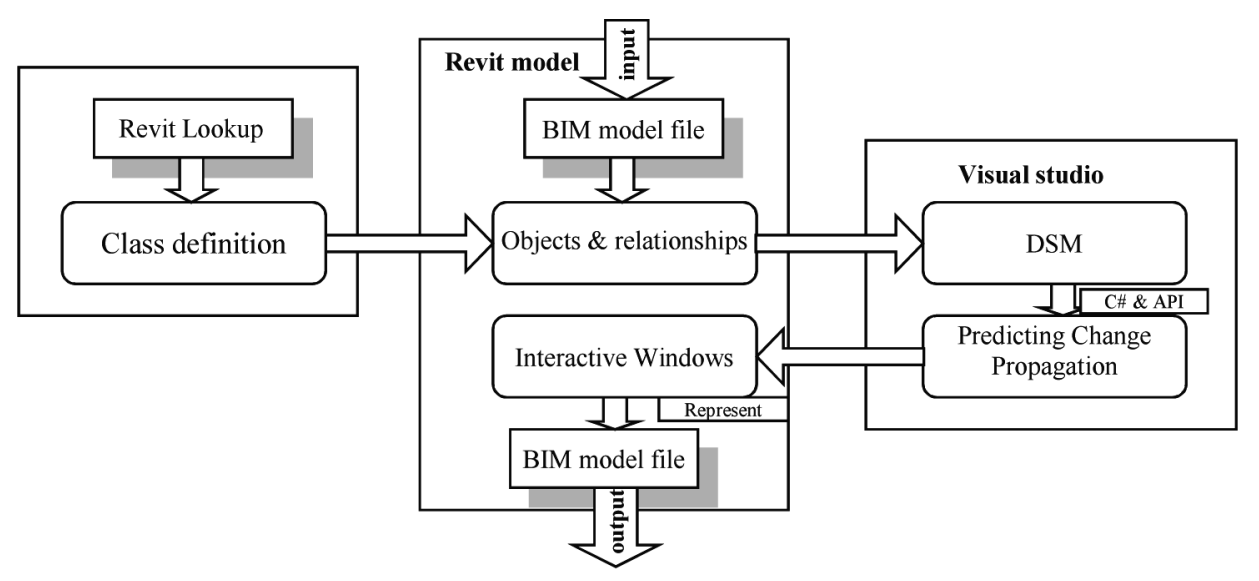

Fig. 12. Integration of DSM with BIM programmatically

Consequently, attributes of the affected component can be determined by using change propagation tree. Based on the assumption that the change propagation follows the spatial links, which have been defined based on dependencies relations DSM, it can be programmed in a way that can visually represent the elements affected by change within the Revit.

It must be noted here that the CPM model represent dependencies relations at the categories level ( $a$, $b, \ldots)$, while the representation within Revit will be at the component level $\left(a_{1} \in a, b_{1} \in b, \ldots\right)$, so if geometry of beam changes, the position of adjacent duct will also change basing on dependencies indicated in DSM. However, if there are no an adjacent duct (component) in BIM file, tree change does not contain this element, and it is not represented in Revit (i.e. tree changes are shown in Fig. 11 will not contain $b_{1}$ ).

In addition, the CPM models assume that the element of DSM is visited once along the track. But in this study assumed that the element of DSM can be visited more than once on the track as long as this element has different ID (i.e. it is different component). For example, in Figure 11 the change of the geometry of beam lead to the change of the position of adjacent duct $\left(b_{1}\right)$, changing position of this duct $\left(b_{1}\right)$, in turn, will change position of another duct $\left(b_{2}\right)$, which has joint with first $\left(b_{1}\right)$ and has different ID. Therefore, an attribute of position of duct $(b)$ changes more than once on the track of change because these duct's components are different in representation within the Rivet. Propagation algorithm can be developed and be programmed so that propagation of change continues as long as the element has different ID, also it should be alerted to the repeated loop (re-work). Figure 11 shows a partial change propagation tree were change caused by changing geometry of beam $\left(a_{1}\right)$.

\subsubsection{Calculation of the likelihood of change for the elements change propagation tree}

The likelihood of change for each element of change propagation tree was calculated as in likelihood algorithm that illustrated in Figure 3. The direct likelihood between the components attributes (i.e. the elements of change propagation tree $\left.\left(l_{x i y j}\right)\right)$ is equal to the direct likelihood between the categories of attributes, which components attributes belong to (elements of DSM $\left(l_{x y}\right)$ ).

Figure 11 shows how likelihood of change of each element was calculated through each route as a result of changing geometry of beam $\left(a_{1}\right)$; then, how the ceiling $\left(e_{1}\right)$, which will change its' position in Revit, and the change propagation tree the element belongs $\left(e_{1}\right)$ are represented; and, additionally, it shows the combined calculated likelihood between $a_{1}$ and $e_{1}\left(L_{e 1 a 1}\right)$.

\subsection{Integration DSM with BIM programmatically}

Building Information Model has all parameters and construction components' attributes, each component has a unique ID and, therefore, there is a possibility to export all attributes of a component, to filter and classify these components.

BIM model file is usually the exported file from a BIM application and it contains information of objects used in the product model. The library of class definitions will help to determine the filtered information and required objects parameters to define relationships (i.e. to determine the output of model file). For example, Revit Lookup can be used as it is a ready software tool that enables to show all details of BIM model file components, the components' parameters and the links between them.

The output of BIM, which is filtered and classified, forms the input for generating DSM. By use of a programming language like C\# with API Revit it is possible to develop the DSM model that identifies the affected elements by change and calculates the probability of change according to the previous proposed methodology. The output of the DSM is represented through interactive windows within the Revit where each component, which is likely to change within the interface view, can be identified.

The software tool can be developed in the future in accordance with the proposed method. The user selects component attribute, which he/she wants to change within Revit, as a result, the elements, which attributes 
were changed and their potential of change appear also within Revit. Figure 12 shows the proposed mechanism for programmatic integration.

\section{Conclusions}

The construction industry needs to keep up with the growing demand for improving productivity, efficiency, quality and sustainable development. In this context, BIM plays an advanced and evolving role in construction industry forcing the development of advanced management systems.

This paper describes a developed method to predict the spread of the change. This method enables the modelling of the change process in BIM environment. Based on this modelling, an information model was developed by using parameter-based design structure matrix for predicting change propagation, and the probability of change propagation from a component to another was estimated as in the methodology of the CPM.

The analysis of the ability to track the spread of change within the dependencies of the BIM model .showed the possibility to use the spatial dependencies between the elements and by integrating BIM with the DSM programmatically to support the visual representation of the predicted change within BIM environment.

The developed method has some advantages; it helps project manager to predict the affected components by changing initiating component and to estimate the probability of change. This method also constitutes a checklist, which can determine who should be informed about a change and the sequence of actions that should be taken. In addition, it helps the designer to predict the possibility of change and the way of change by use of the change tree. Thus allows controlling the spread of the change in undesirable directions. Based on proposed model the software tool can be developed within the Revit environment. The tool will let to select the changed component attributes, to get the elements affected by change, the potential of change and track these elements visually within the Revit.

This method has limitations for use, as it does not discuss other types of changes, such as delete or add components, occurrence of more than one change at the same time, the existence of several scenarios for change, or the possibility of modelling the cost of change. Extending the model to explore such issues is another opportunity for further work.

Further, the uncertainty in the dependencies can be studied. There is also possibility to develop the method of change validation by applying several examples of the changes, which are taken from real change databases. Additionally, there is a need to find the way for minimizing the involvement of engineers in initial stages of change management process and to elaborate the efficient scheme for monitoring and coordination of change process in BIM environment.

\section{Acknowledgements}

The work described in this paper was supported by the Tishreen University, Lattakia, Syria. Special gratitude is also extended to those engineers who have responded to and contributed their valuable input in completing the matrix.

\section{Disclosure statement}

No potential conflict of interest was reported by the authors.

\section{References}

Asl, M. R.; Zarrinmehr, S.; Bergin, M.; Yan, W. 2015. BPOpt: a framework for BIM-based performance optimization, Energy and Buildings 108: 401-412. https://doi.org/10.1016/j.enbuild.2015.09.011

Azhar, S.; Carlton, W. A.; Olsen, D.; Ahmad, I. 2011. Building information modeling for sustainable design and LEED ${ }^{\circledR}$ rating analysis, Automation in Construction 20(2): 217224. https://doi.org/10.1016/j.autcon.2010.09.019

Browning, T. R. 2001. Applying the design structure matrix to system decomposition and integration problems: a review and new directions, IEEE Transactions on Engineering Management 48(3): 292-306. https://doi.org/10.1109/17.946528

Clarkson, P. J.; Simons, C.; Eckert, C. 2004. Predicting change propagation in complex design, Journal of Mechanical Design (Transactions of the ASME) 126(5): 788-797. https://doi.org/10.1115/1.1765117

Dave, B.; Kubler, S.; Främling, K.; Koskela, L. 2016. Opportunities for enhanced lean construction management using Internet of Things standards, Automation in Construction 61: 86-97. https://doi.org/10.1016/j.autcon.2015.10.009

Davies, R.; Harty, C. 2013. Implementing 'Site BIM': a case study of ICT innovation on a large hospital project, Automation in Construction 30: 15-24.

https://doi.org/10.1016/j.autcon.2012.11.024

Derakhshanalavijeh, R.; Teixeira, J. M. C. 2017. Cost overrun in construction projects in developing countries, gas-oil industry of Iran as a case study, Journal of Civil Engineering and Management 23(1): 125-136. https://doi.org/10.3846/13923730.2014.992467

Dowsett, R. M.; Harty, C. F. 2013. Evaluating the benefits of BIM for sustainable design: a review, in Proceedings of the $29^{\text {th }}$ Annual ARCOM Conference.

Eckert, C.; Clarkson, P. J.; Zanker, W. 2004. Change and customisation in complex engineering domains, Research in Engineering Design 15(1): 1-21. https://doi.org/10.1007/s00163-003-0031-7

Giel, B.; Issa, R. 2013. Return on investment analysis of using building information modeling in construction, Journal of Computing in Civil Engineering 27(5): 511-521. https://doi.org/10.1061/(ASCE)CP.1943-5487.0000164

Hamraz, B.; Caldwell, N. H.; Clarkson, P. J. 2012. A multidomain engineering change propagation model to support uncertainty reduction and risk management in design, Journal of Mechanical Design 134(10), 100905. https://doi.org/10.1115/1.4007397

Hamraz, B.; Caldwell, N. H.; Clarkson, P. J. 2013. A matrixcalculation-based algorithm for numerical change propagation analysis, IEEE Transactions on Engineering Management 60(1): 186-198.

https://doi.org/10.1109/TEM.2012.2203307 
Jongeling, R.; Olofsson, T. 2007. A Method for planning of work-flow by combined use of location-based scheduling and 4DCAD, Automation in Construction 16(2): 189-198. https://doi.org/10.1016/j.autcon.2006.04.001

Keller, R.; Eger, T.; Eckert, C. M.; Clarkson, P. J. 2005. Visualising change propagation, in DS 35: Proceedings ICED 05, The $15^{\text {th }}$ International Conference on Engineering Design, 15-18 August 2005, Melbourne, Australia.

Lee, G.; Park, H. K.; Won, J. 2012. D 3 City project - Economic impact of BIM-assisted design validation, Automation in Construction 22: 577-586. https://doi.org/10.1016/j.autcon.2011.12.003

Li, Y.; Zhao, W.; Shao, X. 2012. A process simulation based method for scheduling product design change propagation, Advanced Engineering Informatics 26(3): 529-538. https://doi.org/10.1016/j.aei.2012.04.006

Lin, Y. C.; Lee, H. Y.; Yang, I. T. 2016. Developing as-built BIM model process management system for general contractors: a case study, Journal of Civil Engineering and Management 22(5): 608-621.

https://doi.org/10.3846/13923730.2014.914081

Ma, S.; Jiang, Z.; Liu, W. 2016. Evaluation of a design property network-based change propagation routing approach for mechanical product development, Advanced Engineering Informatics 30(4): 633-642.

https://doi.org/10.1016/j.aei.2016.08.002

Martinaitis, V.; Zavadskas, E. K.; Motuzienė, V.; Vilutienė, T. 2015. Importance of occupancy information when simulating energy demand of energy efficient house: a case study, Energy and Buildings 101: 64-75. https://doi.org/10.1016/j.enbuild.2015.04.031

McGraw Hill. 2009. The business value of BIM: Getting building information modeling to the bottom line, in N. W. Young, S. A. Jones, H. M. Bernstein, J. Gudgel (Eds.). McGraw Hill construction. Smart market report [online], [cited 28 November 2016]. Available from Internet: http://fiatech.org/images/stories/research/2009_BIM_ SmartMarket Report.pdf

Motuzienè, V.; Rogoža, A.; Lapinskienė, V.; Vilutienė, T. 2016. Construction solutions for energy efficient single-family house based on its life cycle multi-criteria analysis: a case study, Journal of Cleaner Production 112: 532-541.

https://doi.org/10.1016/j.jclepro.2015.08.103
Oh, M.; Lee, J.; Hong, S. W.; Jeong, Y. 2015. Integrated system for BIM-based collaborative design, Automation in Construction 58: 196-206. https://doi.org/10.1016/j.autcon.2015.07.015

Poirier, E. A.; Staub-French, S.; Forgues, D. 2015. Measuring the impact of BIM on labor productivity in a small specialty contracting enterprise through action-research, Automation in Construction 58: 74-84. https://doi.org/10.1016/j.autcon.2015.07.002

Sacks, R.; Kaner, I.; Eastman, C. M.; Jeong, Y. S. 2010. The Rosewood experiment - Building information modeling and interoperability for architectural precast facades, Automation in Construction 19(4): 419-432. https://doi.org/10.1016/j.autcon.2009.11.012

Shankar, P.; Morkos, B.; Summers, J. D. 2012. Reasons for change propagation: a case study in an automotive OEM, Research in Engineering Design 23(4): 291-303. https://doi.org/10.1007/s00163-012-0132-2

Shourangiz, E.; Mohamad, M. I.; Hassanabadi, M. S.; Banihashemi, S. S.; Bakhtiari, M.; Torabi, M. 2011. Flexibility of BIM towards Design Change, International Proceedings of Economics Development \& Research 15(2): 79-83.

Steward, D. V. 1981. The design structure system: A method for managing the design of complex systems, IEEE Transactions on Engineering Management 28: 71-74. https://doi.org/10.1109/TEM.1981.6448589

Suermann, P. C.; Issa, R. R. 2009. Evaluating industry perceptions of building information modelling (BIM) impact on construction, Journal of Information Technology in Construction (ITcon) 14(37): 574-594.

Sun, M.; Senaratne, S.; Fleming, A.; Motowa, I.; Yeoh, M. L. 2006. A change management toolkit for construction projects, Architectural Engineering and Design Management 2(4): 261-271.

Wang, J.; Wang, X.; Shou, W.; Chong, H. Y.; Guo, J. 2016. Building information modeling-based integration of MEP layout designs and constructability, Automation in Construction 61: 134-146.

https://doi.org/10.1016/j.autcon.2015.10.003

Zhao, Z.-Y.; Lv, Q.-L.; You, W.-Y. 2008. Applying dependency structure matrix and monte carlo simulation to predict change in construction project, in Proceedings of the Seventh International Conference on Machine Learning and Cybernetics, IEEE, 2: 670-675.

Lama Adel SAOUD. Is a PhD student at the Department Engineering and Construction Management, Faculty of Civil Engineering, Tishreen University. Her research interests include change management and building information modeling.

Jamal OMRAN. Is an Associate Professor at the Department Engineering and Construction Management, Faculty of Civil Engineering, Tishreen University. His research interests include construction management, decision making methods and building information modeling.

Bassam HASSAN. Is a Professor at the Department Engineering and Construction Management, Faculty of Civil Engineering, Tishreen University. He served as vice president of Tishreen University for scientific research and Postgraduate studies; director of Coastal Region Branch of the General Company for Studies and Technical Consultation in Syria (Partial Secondment). He supervised and managed several organizational studies in the cities of Latakia and Tartous. His research interests include project management and construction technology.

Tatjana VILUTIENE். Associate Professor in the Department of Construction Technology and Management, Vilnius Gediminas Technical University (VGTU). She received the MS degree (2000) and PhD degree (2004) from the Vilnius Gediminas Technical University. She published articles on the application of multiple-criteria decision-making methods in construction project management, energy-saving construction, sustainable development and facilities management. Her current research interests include project management, construction knowledge management, building information modeling, BIM related topics.

Arvydas KIAULAKIS. PhD candidate in the Department of Construction Technology and Management, Vilnius Gediminas Technical University (VGTU). He received MS degree in the Construction Technologies and Management program from VGTU in 2016. He has been involved in construction projects as structure designer. His published research is centered on area of BIM application in design and construction. His current research interests include building information modeling, design and construction management in practice, and the practice of BIM applications. 